\title{
Digital leadership in action in a hospital through a real time dashboard system implementation and experience
}

\author{
Jack Weiner ${ }^{1}$, Mohan Tanniru*2, Jiban Khuntia ${ }^{3}$, David Bobryk ${ }^{4}$, Mehul Naik ${ }^{4}$, Kenneth LePage ${ }^{4}$ \\ ${ }^{1}$ St Joseph MercyHealth Systesm, Pontiac, Michigan, United States \\ ${ }^{2}$ Oakland University, Rochester, Michigan, United States \\ ${ }^{3}$ University of Colorado, Denver, United States \\ ${ }^{4}$ St. Joseph Mercy Health Sytems, Pontiac, Michigan, United States
}

Received: February 29, 2016

DOI: $10.5430 /$ jha.v5n4p34
Accepted: April 18, 2016

Online Published: April 28, 2016

URL: http://dx.doi.org/10.5430/jha.v5n4p34

\begin{abstract}
Background: Regulatory and competitive pressures and the need for cross-organizational data sharing are demanding that hospital leaders create a data-driven decision making culture to improve performance. Using an innovation assimilation strategy framework, this paper describes how a hospital used its implementation of a Real Time Dashboard System (rtDashboard) to improve performance, change its organizational culture and put it on a path towards digital leadership (DL).

Objective: Implement an rtDashboard system that can support a data-driven decision making culture for performance improvement while engaging business and information technology (IT) leaders in DL practice.

Results: The rtDashboard contributed significantly to monitoring hospital performance and influenced change in unit level decision making that was aligned with hospital goals. The rtDashboard implementation not only provided substantial performance improvement and quality benchmarking, but also changed the responsibility and accountability culture and helped the hospital put in practice DL principles to support future innovations.

Conclusions: DL through rtDashboard is a demonstration of how a hospital can seek and strive for excellence. As much as dashboards are pivotal to organizational performance monitoring at the senior leadership level, the process used to diffuse it to every operational unit in support of a data-driven decision making culture showcases how hospital executives and IT leaders can work together to continually align and re-align their strategies to reach organizational goals - the core of DL practice.
\end{abstract}

Key Words: Digital leadership, RtDashboard, Goal alignment, Hospital performance, Innovation assimilation strategies

\section{INTRODUCTION}

The Service-Dominant Logic perspective is encouraging all firms to view themselves as service firms by creating value around the products they sell. ${ }^{[1,2]}$ Advanced digitization opportunities are adding impetus to such a service-driven perspective by empowering customers, through their use of social media tools and the Internet, to demand digital (Information technology [IT]-enabled) services. Even firms that are traditionally product-oriented are extending their supply chain to take advantage of digitization opportunities in reducing their operational costs by co-producing digital services with suppliers and partners, and in developing differentiated services by co-creating value propositions with customers. ${ }^{[3]}$ The drive of the health care sector towards developing services that address the needs of stakeholders, patients, government, and others is similar to challenges faced

\footnotetext{
*Correspondence: Mohan Tanniru; Email: tanniru@ oakland.edu; Address: School of Business Administration, Oakland University, Rochester, MI, United States.
} 
by other sectors that are traditionally knowledge-intensive and service-driven.

Health care stakeholders from the policy to practice levels are realizing that care delivery needs to become patientcentric, service-oriented, and value-based. The enactment of the Health Information Technology for Economic and Clinical Health (HITECH) Act in 2009 has led to the practice of meaningful use of health information technologies and performance metrics (defined by Healthcare Effectiveness Data and Information Set: HEDIS, http: //ww w. ncqa . org/HEDISQualityMeasurement . aspx). Subsequently, the enactment of the Patient Protection and Affordable Care Act (https://www .healthcare.gov/glossar $y / a f f o r d a b l e-c a r e-a c t /)$ in 2010 has led to changes in the practices of hospitals and primary care physicians to drive better health outcomes. The regulatory environment will continue to shift cost reimbursement from a "fee for service" model to "bundled payments" that cover care both inside and outside the hospital walls. Incentives based on patient satisfaction and penalties for early patient readmission will continue to put pressure on hospitals to seek improvements in continuity of care.

Setting a goal to not just survive, but to thrive and grow in this evolving health care landscape, the senior leadership at St Joseph Mercy Oakland (SJMO) adopted a vision of providing high quality care along with excellent safety and patient engagement in support of continuity of care. To realize this vision, the hospital had to first restructure its internal reporting system using a technology platform so it could start to get an integrated view of hospital operations and help leadership adapt quickly to market and regulatory changes. In addition, the technology platform with data sharing capabilities had to change the organizational culture by encouraging transparency and accountability, along with continual and rapid alignment of organizational goals with functional or unit level performance targets.

Resource-based theory suggests that firms that strive to create differentiated value have to build flexibility within their processes to manipulate their internal and partner resources. ${ }^{[4,5]}$ In this regard, IT can build flexibility in its architecture and functions to leverage technological advances and influence business performance. ${ }^{[6,7]}$ Firms need to take advantage of such IT flexibility to evolve their business strategies and structure as they develop new services to meet changing and digitally-empowered customer expectations. Today's evolving technology landscape has to make both business and IT leaders align and re-align their strategies at a faster speed to take advantage of opportunities. ${ }^{[8]}$ Such an engaged and continuous commitment of both business and IT leaders to

Published by Sciedu Press take advantage of new digital services is referred to here as "digital leadership (DL)" practice.

In this paper, we will discuss how a 443-bed community teaching hospital (SJMO) used DL practice to bring about a change in its organizational culture of transparency and accountability with the implementation of a Real Time Dashboard System (rtDashboard). With the implementation of rtDashboard, the SJMO leadership's vision was to move from decisions made based on historical data to those made using real-time data coming from disparate and multiple systems.

The next section will discuss how an innovation assimilation strategy framework was used to diffuse a number of innovations at SJMO: rtDashboard, organizational culture and DL practice. The third section illustrates the dashboard's evolution and how its assimilation strategy was used to not only improve hospital performance but also diffuse the second innovation: organizational culture. The fourth section shows how the IT and business leadership at SJMO used the diffusion of both these innovations to pilot its third innovation: DL practice.

\section{Assimilation STRATEgy FRAMEWORK FOR DIFFUSION OF INNOVATIONS AT SJMO}

Environmental factors such as dynamism (high degree of uncertainty and equivocality/volatility) and heterogeneity (responses of different stakeholders needed to develop a coherent strategy) have long become the driving forces for the adoption of performance dashboards, such as executive information systems (EIS). ${ }^{[9]}$ Today dashboard technologies are used effectively by many industries for sharing information and allowing real-time decision making. The SJMO leadership has seen how the hospital environment has changed over time, both in terms of its dynamism and heterogeneity. These changes posed challenges for hospital performance, specifically if its employees continued to operate "in silos" with no transparency in the way they share information and engage in collective decision making. SJMO leadership was convinced that it needed to diffuse rtDashboard as an innovation to support real-time decision making in a collaborative culture.

In extant research, the process of innovation is conceptualized as comprising three phases: initiation, adoption, and implementation. ${ }^{[10-12]}$ While the first phase is used to assess the business value of an innovation (e.g. rtDashaboard), the second phase is intended to explore its adoption by an individual or a unit within a firm, and the third phase looks to the subsequent diffusion of the innovation to all who need to adopt it for the firm to realize the full potential of the 
innovation, i.e., the spread of the innovation through the target social system. ${ }^{[13]}$ Diffusion of new technologies such as rtDashboard can follow a three step innovation implementation strategy, ${ }^{[14]}$ which includes: preliminary experimentation among a few early adopters, organizational response to support broader diffusion among several stakeholders, and institutionalization for its eventual use by all involved.

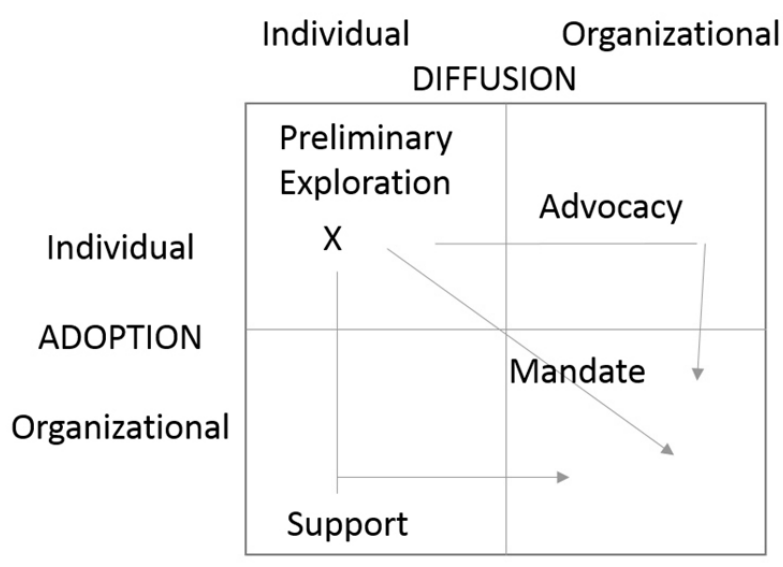

Figure 1. Framework for innovation assimilation

Using several case studies, Agarwal, Tanniru, and Wilemon $^{[15]}$ developed assimilation strategies such as support vis-à-vis advocacy to help a firm move from the preliminary experimentation phase to the institutionalization phase when introducing innovative products or services. Figure 1 is a representation of these two approaches. The top left quadrant is where an individual or group adopts a new innovation in the experimentation phase. An organization can proactively support the diffusion of this innovation through advocacy (moving from the top-left quadrant to the top-right quadrant) or support (moving from the top-left quadrant to the bottom-left quadrant). The support strategy is slow, peer-topeer diffusion, while the advocacy strategy is a purposeful, organization-driven approach. The goal eventually is to make all necessary stakeholders adopt the innovation (moving to the bottom-right quadrant). One method to move quickly from exploration to full adoption is through an organizational mandate, which is often used when the speed of diffusion is critical.

Organizational change theory suggests that a purposeful and proactive approach is needed if a firm is to bring about significant change, such as in its culture. Viewing "change of culture" itself as an innovation, SJMO had to assess the impact of this innovation on the organizational structure and actively control and manage its assimilation. ${ }^{[12]}$ The impact of an innovation can be extensive, important, or established, ${ }^{[16]}$ depending on how it influences the organization.
The impact can be assessed based on breadth, i.e. adoption is needed by a large number of employees, or depth, i.e. adoption changes the operational or work system. ${ }^{[17]}$ Agarwal et al. ${ }^{[15]}$ also identify factors that can measure the impact: product vis-à-vis process innovation, adopter characteristics (leaders vis-à-vis followers), and implementation complexity (the number of people impacted and dependency of each person's adoption behavior on others and the overall task). While the adoption of rtDashboard is a product innovation with a broader impact, seeking cultural change (a process innovation) can have a deeper impact, as it is going to change the way employees and managers use the dashboard to alter their work behavior. As we discuss in section 3, SJMO has decided to use a hybrid approach (advocacy-support) to bring about the diffusion of cultural change.

Uncertainty and equivocality are prevalent in hospitals, as they have to deal with a high degree of competitive rivalry and face environmental dynamism with multiple sets of regulations, patient expectations, and changing reimbursement policies. Many clinical units that comprise a hospital complex are heterogeneous in nature, with significant operational differences, and view clinical processes and financial/administrative processes to be different. The commingling of these two - connecting clinical treatment and patient care to cost, quality, and satisfaction metrics (all impacting the financial performance) - is somewhat of a radical change/transformation. Such a transformation requires a continual change in the way hospital and IT leadership look for new innovations besides the current rtDashboard and diffuse them into the organization. This means a change in the current business and IT leadership practice and the testing of a new approach ("DL practice") to address both uncertainty and equivocality. This is addressed in section 4.

The next section will discuss in greater detail how the dashboard technology (a product innovation) has evolved from its inception to where it is today, and how it has helped SJMO diffuse a change to its organizational culture (a process innovation).

\section{DAShboARd SySTEM AdOption, DifFU- SION, AND IMPLICATIONS}

Using advanced digitization to align the actions of multiple units with organizational goals is a major challenge, especially in hospitals where unique care related specialties often dictate both clinical and treatment operations and financial reimbursements. However, as the focus of hospitals shifts to care optimization to address a wide range of organizational metrics, there is a greater need for accountability across units to ensure that their action plans are aligned with these met- 
rics. In support of this effort, SJMO has implemented its first innovation: rtDashboard using the assimilation strategy (pilot, to advocacy, and then to support strategies) discussed in this section. The timeline for the implementation is shown in Table 1.

Table 1. Timeline of rtDashboard implementation

\begin{tabular}{|c|c|c|}
\hline Timeline & rtDashboard Impleme & ation \\
\hline Mar-11 & $\begin{array}{l}\text { Purchase and } \\
\text { acquisition of } \\
\text { rtDashboard }\end{array}$ & $\begin{array}{l}\text { As a part of a larger patient flow initiative that was started in 2010, the goal of the software is to track organizational } \\
\text { capacity in real time. Patient flow initiative is a program that was put in place to help improve capacity management } \\
\text { issues, i.e., the capacity levels by units. For example, a unit can hold } 40 \text { patient beds, whereas the current census is } 35 \\
\text { patients. A group of users was selected by senior leadership to be a part of the rtDashboard team and was trained by the } \\
\text { software firm. A list of metrics was identified as a starting point to develop rtDashboards. Capacity management was } \\
\text { the first dashboard created because it had a high impact on the organization, met a large organizational objective, and } \\
\text { was stored in a database available to query (teletracking). }\end{array}$ \\
\hline May-11 & Metric selection & $\begin{array}{l}\text { The team chosen evaluated the metrics (shown in Table 2) in terms of the information currently available and the value } \\
\text { to the organization, specifically selecting those with high impact. For this reason, hospital's capacity management and } \\
\text { patient flow logistics system were selected, so they can leverage data from the Teletracking software and have high } \\
\text { impact. }\end{array}$ \\
\hline May-July & Automation of inputs & $\begin{array}{l}\text { A new software with a stored procedure capability to pull data from the current Teletracking software provided } \\
\text { automation of input to the rtDashboard. This led to the selection of the next metric: patient satisfaction using data from } \\
\text { the Press Ganey system. The data presented by rtDashboard allowed unit comparisons with other units and supported } \\
\text { industry-wide benchmarking. This led to friendly competition among managers. }\end{array}$ \\
\hline 2011 & $\begin{array}{l}\text { Introduction of other } \\
\text { metrics }\end{array}$ & $\begin{array}{l}\text { Other metrics added to the dashboard were: how long a patient was in observation, EVS turnaround time metrics, ER } \\
\text { turnaround time metrics, and clinical quality metrics, including the federal government's Meaningful Use metric (from } \\
\text { HITECH Act of 2011). }\end{array}$ \\
\hline Jul-11 & $\begin{array}{l}\text { Operational } \\
\text { innovations }\end{array}$ & $\begin{array}{l}\text { After four months of training on rtDashboard, the organization started multi-disciplinary rounds and daily huddles } \\
\text { utilizing rtDashboards. The goal of multi-disciplinary rounds was to give unit managers, especially nurse managers, } \\
\text { who in the past managed their units retrospectively using past data a chance to respond quickly to changes because they } \\
\text { could now see real time data. Unit huddles allowed nurse managers to use real time metrics to change their operations. } \\
\text { Six months after training on rtDashboard, key strategic and key process improvement (KSI and KPI) indicators were } \\
\text { loaded into rtDashboard and were used in the unit huddle. This is consistent with the adoption of Hoshin Konri as the } \\
\text { guiding methodology. }\end{array}$ \\
\hline Sep-11 & $\begin{array}{l}\text { Technology challenges } \\
\text { continue to persist }\end{array}$ & $\begin{array}{l}\text { Even with stored procedures pulling data, only } 10 \% \text { of the rtDashboard (e.g. key volume indicators and capacity) was } \\
\text { getting real time data through automatic extraction, while } 90 \% \text { of the data was collected using Excel file uploads. }\end{array}$ \\
\hline Fall 2012 & BI Team formation & $\begin{array}{l}\text { A year and a half after the KSI/KPI were added to the unit huddle, a business intelligence team was created to start } \\
\text { prioritizing data requests for new dashboard development and maintenance. }\end{array}$ \\
\hline $\begin{array}{l}\text { Spring } \\
2013\end{array}$ & $\begin{array}{l}\text { Attempt to address } \\
\text { technology challenge }\end{array}$ & $\begin{array}{l}\text { It was determined that the work effort needed to upload Excel files on a daily basis to the rtDashboard was very } \\
\text { cumbersome and a process was needed to automate the data input in order to generate real time metrics. The upgraded } \\
\text { Teletracking software was explored to see if Excel files could be automated for direct input into the dashboards. This } \\
\text { capability was lacking at that time. A contract was signed with a company called Netlink, which specializes in IT } \\
\text { solutions for such integration. After one year of engagement and assessment, the contract was terminated. }\end{array}$ \\
\hline Fall 2014 & $\begin{array}{l}\text { Recruitment of } \\
\text { business intelligence } \\
\text { (BI) staff }\end{array}$ & $\begin{array}{l}\text { A BI staff member was recruited to help support the programming needed to automate data input to rtDashboard. Press } \\
\text { Ganey was the first dashboard that was automated. Work being done at the quality institute was then leveraged in the } \\
\text { automation of the dashboard applications. The quality institute is an internal team of SJMO, which includes } \\
\text { programming skill sets. This team was able to accept a Press Ganey data file and clean the file up prior to sending it out } \\
\text { to SJMO for patient satisfaction metrics. }\end{array}$ \\
\hline $\begin{array}{l}\text { Spring } \\
2014\end{array}$ & $\begin{array}{l}\text { Enhancing the } \\
\text { automation effort }\end{array}$ & $\begin{array}{l}\text { By this time, three new reporting services were purchased from Teletracking, and the BI Team worked with the vendor } \\
\text { to gain access to the stored procedures that were needed as a front end to automate the Excel applications. This led to } \\
\text { automating the capacity management and enhanced EVL/Transport tracking. This effort changed dashboard } \\
\text { automation from } 10 \% \text { to } 80 \%-85 \% \text {. }\end{array}$ \\
\hline $\begin{array}{l}\text { Early } \\
2015\end{array}$ & $\begin{array}{l}\text { Legacy system } \\
\text { integration }\end{array}$ & $\begin{array}{l}\text { SJMO was finally able to get Cerner (legacy system) to integrate the corporate system data with the dashboard for } \\
\text { direct access to some of the data. }\end{array}$ \\
\hline Jul-15 & External recognition & SJMO received a national award for rtDashboard, Innovator Finalist award as a top six healthcare IT project in the US. \\
\hline Fall 2015 & $\begin{array}{l}\text { Regional strategy for } \\
\text { rtDashboard }\end{array}$ & $\begin{array}{l}\text { rtDashboard has become a part of the regional strategy for St Joseph Mercy Health System South Eastern Michigan, } \\
\text { and work has begun to create dashboards for Ann Arbor, Livingston, Chelsea, and Livonia. The preliminary effort } \\
\text { included some source systems (Cerner, Press Ganey) and some different systems (Teletracking/Armark), all to become } \\
\text { a part of a basic package of dashboards to be deployed for the region. Some systems were the same in the region, which } \\
\text { became easy to replicate, and some were new dashboard applications. }\end{array}$ \\
\hline
\end{tabular}




\subsection{Pilot phase}

The leadership strongly believed in the philosophy of Hoshin Kanri and used its toolkit of forms, metrics and reports, targets, and guidelines to align organizational goals with unit level performance. In practice, this encouraged employees to analyze situations, create plans for improvement, conduct performance checks, and take appropriate action based upon any uncovered variances.

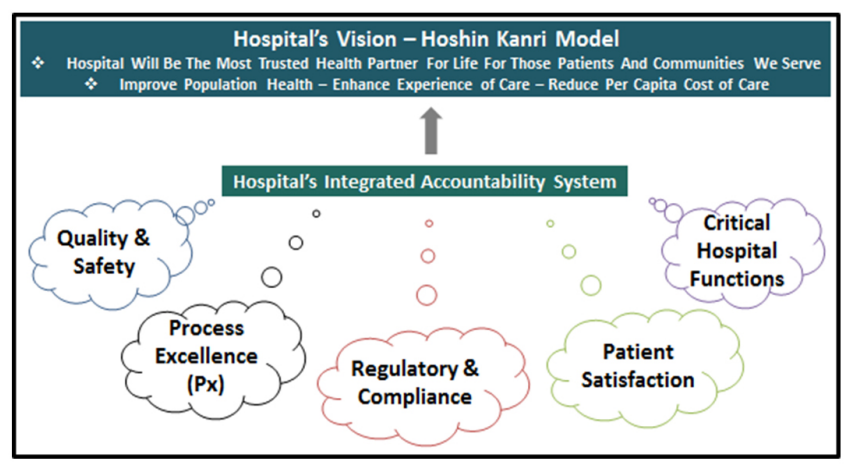

Figure 2. RtDashboard as part of integrated accountability system and aligned to Hoshin Kanri model

Senior leadership - in collaboration with the medical staff set the vision and high-level targets for the organization as a whole (see Figure 2). At each tier of the management hierarchy, the high level goals were translated into a set of coherent, consistent, understandable, and attainable actions that could be cascaded to each subsequent level of the hospital. At each grade, managers and employees personally participated in the translation of the strategy into detailed action plans to attain their respective targets. These targets were reviewed and interpreted on a daily basis. Both through the planning and policy deployment, this integrated accountable system became the basis for tracking various performance metrics and providing opportunities for goal alignment, resource optimization across care processes, the elimination of siloed thinking, and priority setting. In other words, a technology product innovation helped support a process innovation (change in the planning process).

During the first few months (March to July, 2011), the IT leadership used a relatively small financial investment and internal resources to purchase an rtDashboard platform. This platform supported the analysis of a few currently managed operational metrics (e.g. capacity management and patient satisfaction) and provided these to senior unit managers in order to get an early buy-in from them on both the value and need for aligning unit operations and hospital administration's organizational goals along a few key performance metrics.
At a department/process level, these real-time metrics were to be used for continuous improvement. On the huddle boards, the daily metrics were shown to front-line associates regarding their unit performance in a user-friendly and intuitive manner (see Figure 3). For example, some key metrics monitored by staff included:

- Current emergency room/inpatient census - What is the current hospital census (by unit)? How many patients are in the emergency room? The emergency waiting room?

- Patient volume - How many admissions/emergency visits occurred yesterday? What about monthly and/or year-to-date? How many were brought by emergency medical service companies?

- "Door-to-doc" time in the emergency room - How long do patients wait to be seen by physicians or advanced practice providers in the emergency room? Operationally, how does this impact staffing levels, patient safety, and patient/employee satisfaction?

- "Decision to admit to departure" in the emergency room - How long does it take from the time the emergency physician decides to admit a patient to the time the patient actually leaves the emergency room to an inpatient bed?

- Number of patients who leave without being seen (LWBS) in the emergency room - Functionally, LWBS visits are an indication of emergency room crowding and associated with longer wait times.

- Department-specific quality metrics (falls, hand hygiene compliance, etc.).

- Department-specific patient satisfaction scores.

\subsection{Advocacy approach - support health care user adap- tation}

In the next one year (August 2011 - Sept 2012), the leadership developed internal organizational practices, such as daily and periodic rounds, to get managers to openly discuss their unit level performance, which was enabled by transparent sharing of performance data via rtDashboard. Executive leadership was engaged in these periodic rounds to make clear its commitment to use real time data sharing and unit level activity tracking as a source for collaboration and continual improvement, and not a distraction or cause of blame games. The leadership also encouraged management at various tiers to develop new dashboard applications using a number of other metrics from available data (see metrics Table 2).

IT leadership continued to support dashboard applications by setting up a committee to assign priorities among various 
requests based on their organization-wide impact and/or to address unit level efficiencies. The rtDashboard, with its ability to display trends (daily, weekly, monthly, etc.), has started to help monitor appropriate metrics and performance measures relative to key performance indicators.

Table 2. Metrics evaluation data sources for rtDashboard

\begin{tabular}{|c|c|c|}
\hline Metric & Data Source & Purpose \\
\hline Global Operating Characteristics & All & \\
\hline $\begin{array}{l}\text { Department Operating Characteristics } \\
\text { (Defined by Department) }\end{array}$ & Vista, Teletracking & Volume Trending, Staffing, Productivity \\
\hline Physician Network Performance by Practices & NextGen, Business Objects, MIDAS & Referrals, RVU’s, Patient Satisfaction \\
\hline $\begin{array}{l}\text { Nursing Unit } \\
\text { - Financials } \\
\text { - Customer Satisfaction } \\
\text { - Clinical Defects Falls } \\
\text { - Bed Sores } \\
\text { - Environment of Safety }\end{array}$ & Press Ganey, Business Objects, MIDAS & Core measure performance \\
\hline IT Implementation & Excel, Quickbase, MIDAS & $\begin{array}{l}\text { Budget, Milestone Completion } \\
\text { Percentage, System Usage Reports }\end{array}$ \\
\hline Lean Operations Metrics & Excel, MIDAS, Case Tracker & \\
\hline $\begin{array}{l}\text { Utilization Process Management } \\
\text { - ER Closure } \\
\text { - Bed Turnover }\end{array}$ & Teletracking & \\
\hline Observation Utilization & Teletracking & \\
\hline $\begin{array}{l}\text { Matrix of Change Expectation } \\
\text { - Department Level Review of System } \\
\text { Modifications and System Deployment }\end{array}$ & MIDAS & \\
\hline Status of Recidivism Program & MIDAS & \\
\hline Supply Chain Status & Lawson & \\
\hline Report Turn Around Times & MCL, MIDAS, RADNET, Case Tracker & \\
\hline $\begin{array}{l}\text { Services Standards } \\
\text { - Delays/Back Logs - Performance Metrics }\end{array}$ & Teletracking, MIDAS, Press Ganey & \\
\hline
\end{tabular}

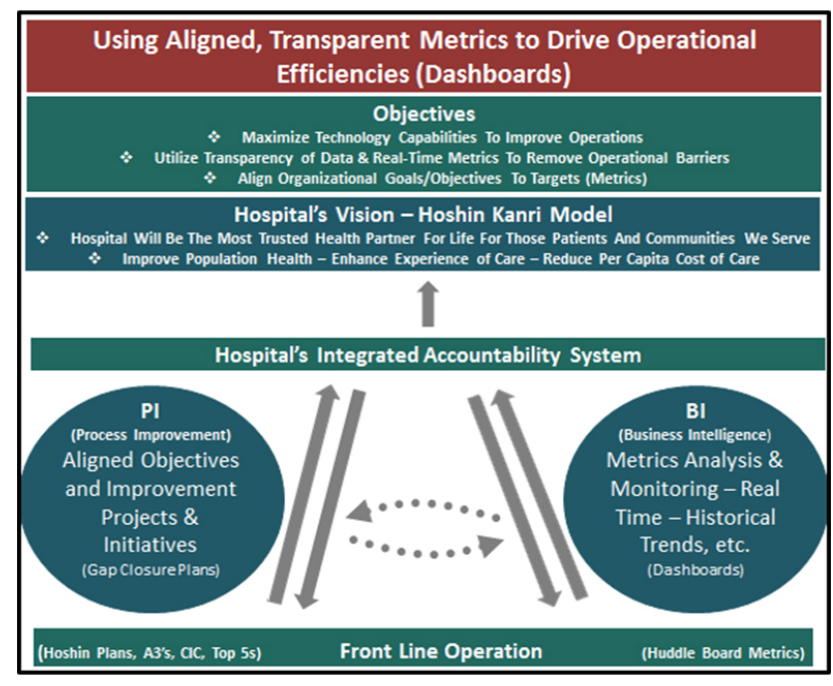

Figure 3. RtDashboard aligned to objectives and metrics

Besides physicians and hospital administrators using realtime monitoring to address bottlenecks and identify key conPublished by Sciedu Press straints, the key metrics were displayed in high-footprint areas throughout the hospital. This showed SJMO's commitment is instill a culture of collective responsibility for hospital performance among all its employees, and a willingness to share this information with all its stakeholders openly.

\subsection{Support approach - technology standardization for sustained application development}

Eighteen months after the dashboard's introduction, the focus of IT leadership shifted to technology platform standardization and data integration from multiple systems. These technology issues had taken a back seat up to this time, with the early focus being on the diffusion of technology to the user population. Once a certain maturity in usage was reached, the IT leadership started to look for greater system efficiencies through standardization and portability to support future dashboard applications.

Prior to rtDashboard, the data shared among organizational 
units was in Excel file format sent through secured email. After its implementation, rtDashboard was able to integrate data, often through manual input, from multiple sources into a single chart in real-time using speedometer charts with easyto-understand metrics displayed in all units. However, over time these data files needed automation to gain operational efficiencies and look for standardization in terminology. As the evolution in Table 1 shows, this was the focus during the next 18 months (Sept 2013 to early 2015). With all the associated technology developments, the dashboard product today:

- Is available on every computer in the hospital so everyone in the organization is aware of the long-term strategic goals and key performance metrics;

- Has a web-based user interface that supports all browser types and devices, including mobile devices on Android and iOS;

- Has an ability to be set up with role-based permissions. Sensitive data can be seen only by those who need the access;

- With real-time user filtering to drill down to the granular level, supports viewing historical data based on select criteria, supports synchronized and multiple pivots, helps set up input parameter controls, etc.

With connectivity established through ODBC link to the source database (Oracle \& Microsoft SQL Server databases), data can be queried and results loaded onto staging databases via ETL packages. The rtDashboard product today provides real-time alerts when certain conditions are met and sends these alerts via email and/or SMS text to individuals or groups of users based on the established escalation levels for potential action.

The success of the diffusion of rtDashboard in SJMO is measured by how well it provides solid tangible benefits to the hospital, as well as its ability to support a cultural change by align organizational goals with unit level actions. Business leadership, during this time, started to generate information on the benefits realized through the rtDashboard technology. Some of the benefits included:

(1) Enhanced ability to manage through metrics - Successful management requires developing appropriate metrics to measure performance relative to objectives. For example, SJMO's "decision to admit to departure" for the Lean-Track patient improved from 164 minutes (Jan 12) to 112 minutes (Feb 14), a 32\% improvement. The "decision to admit to departure" for Acute-Track patients improved from 343 minutes (Jan 12) to 223 minutes (Feb 14), a 35\% improvement.
(2) Empowering employees - By having a clear definition of the KPIs, employees are empowered to achieve organizational objectives. For example, after obtaining the Level II Trauma Service Certification Designation for the organization, closely monitoring trends of daily/monthly EMS ambulance run has become more important, and by making this KPI visible the hospital was able to see an improvement of $29 \%$ in only two years (894 in Feb 13 to 1,244 in Jan 15).

(3) Dashboards vis-à-vis Reports - A common notion is that a dashboard is a collection of reports on a single screen/paper with some charts in the mix. The rtDashboard is utilized as an effective means for communicating information and delivering dynamic insight from the data through drill down capability.

(4) Real-time alerts/analytics - Real-time analytics on the dashboard allows users to perform dynamic calculations on real-time data. Using conditional logic and analytical ability, users are able to receive alerts at specific points in time via email and/or an SMS text message, without users connecting to the system. For example, the number of patients who left without being seen (LWBS) in the emergency room improved from almost 4\% (165 patients in Mar 12) to $1.25 \%$ (64 patients in Feb 14) .

(5) Ease of use/scalability - rtDashboard is intuitive and user-friendly, and the plug-in-based flash engine in rtDashboard is designed to provide a fast response in an interactive mode.

\subsection{Infusion for wider dissemination - scaling for regional adoption}

Developing technology for management use in a multihospital environment calls for portability and scalability of rtDashboard to other hospitals or to the entire Trinity health system, if benefits warrant such a move. One of the goals of SJMO leadership is to make the use of such dashboard applications widespread among other hospitals, if the benefits are portable and the application is scalable. SJMO used a very small initial investment of $\$ 29,430$, much below the health system capital threshold of $\$ 50,000$ (refer to Table 3 for detailed breakdown, cost based on Fiscal Year 2012 actual expenses), along with internal business intelligence staff to make the initial investment affordable. By using internal IT and management teams, there was significant learning that came with both incremental and significant jumps in the implementation of the dashboard. This made both the IT and business leadership better prepared to work with the regional group for scaling rtDashboard for wider applicability. 
Table 3. Breakdown of rtDashboard cost

\begin{tabular}{ll}
\hline Description & Price (\$) \\
\hline Dashboard Server & 5,205 \\
Power User License $(\times 10)$ & 15,000 \\
LCD License (unlimited) & 4,500 \\
Annual Maintenance & 4,905 \\
Total Initial Investment & 29,430 \\
\hline
\end{tabular}

When the approach used for introducing rtDashboard for performance monitoring was identified for expansion as a part of the regional strategy of the St. Joseph Mercy hospital system in Michigan, a business intelligence team was created without adding any additional full-time employees. The members included individuals from various departments such as Patient Placement Center, Clinical Informatics, Quality, Finance, Process Excellence, Outcomes Management, Nursing Education, Desktop Support, and Patient Satisfaction. The low-cost nature of the software makes it feasible for even small, independent hospitals that are looking to improve outcomes, increase performance, and harness the talent in house.

A few challenges have arisen since the effort to scale the rtDashboard to other regions has begun:

- Operational - Livonia never had a daily operational huddle prior to this project, and adoption of new processes is being slowly rolled out. Ann Arbor/Chelsea/Livingston (West Region) had a huddle, but was unable to view metrics in real time or in detail. Given that a health campus like Ann Arbor is spread out and difficult to operationalize a daily personal huddle, they may utilize Web Ex.

- Metrics and Standardization - The Livonia facility uses "mean score" to measure patient satisfaction, while SJMO uses top box scores. Also, metrics chosen initially were focused around people to emphasize peoplecentered care, develop national leadership, encourage effective stewardship and operational excellence, and engage colleagues.

To address these regionalization challenges, three regional teams were formed: (1) A weekly process excellence team gets into the granular level of detail in rtDashboards; (2) A monthly operations team focuses on standardization of metrics and new dashboard creation; and (3) The steering team meets monthly with account executives to give them the status and seek needed guidance to move the regionalization project forward. At this time, the regional dashboard includes a clinical quality scorecard for all of Southeastern Michigan. Trinity Health Strategic Aims and Metrics is the next dashboard to be developed, with data aggregated from the region and drilled down to the individual hospitals within the region.

In summary, after an early pilot phase effort to gain unit manager commitment regarding the need for alignment, an "advocacy" approach was used by hospital leadership to gain commitment from multiple users, with IT providing a "supporting" role. After the usage reached a reasonable threshold, the IT leadership took on an "advocacy" approach to improve technical efficiencies for further deepening the infusion of technology, while the hospital leadership provided a "supporting" role. The use of such a hybrid approach (advocacy followed by support of rtDashboard) is designed to bring about planned changes in SJMO's organizational culture of transparency and accountability. The next section will elaborate further on the changing roles of business and IT leaders and how such changes are characteristic of DL practice.

\section{Adoption OF DL PRACTICE AS AN ORGA- NIZATIONAL INNOVATION}

DL is a practice that supports the adoption, diffusion, and implementation of digital service innovations in organizations. Theories like the technology acceptance model ${ }^{[18-20]}$ are focused on individual level adoption, while technology assimilation models ${ }^{[15,20,21]}$ were studied for organizational level adoption. These models in general assume that the innovation process starts with some early exploration by an individual or a unit and, based on its demonstrated success, gets diffused to others in the organization. ${ }^{[21]}$ In this study, SJMO's diffusion of "rtDashboard" to various users "piloted" the concept of DL practice: the dual role of business and IT leaders in the diffusion of digital service innovations.

DL practice is not about evaluating and delivering a single digital service, but building a culture of leadership that supports agility within the firm to take advantage of opportunities that surface frequently in today's changing technology and customer landscape. Operationally, this calls for effective team work among business and IT leaders.

- In the case study, IT and hospital leaders detected digitization opportunities to address the changing needs of patients in an evolving health care environment.

These needs called for hospital leadership to processes that align organizational and unit level performance, while IT leaders assess the technical viability of using a reasonable dashboard product to support this alignment.

- Once the fulfillment of the hospital need via a digital service (performance dashboard) was viewed as viable (through a pilot effort), both IT and hospital 
leaders simultaneously looked at their resources to operationalize this service.

(1) With a number of external partners developing innovative digital products, IT leadership acquired a product from an external vendor and used internal resources to quickly deliver on a digital service for hospital leaders and unit managers.

(2) Simultaneously, hospital leadership changed the reporting and decision making processes using an "entrepreneurial" mindset: how to use financing, partners, organizational governance, and risk mitigation to bring about the change needed in the hospital culture in support of evolving needs.

- IT leadership, while focusing early on user enablement through technology, started to focus on robust technology standardization and integration in the later stages to potentially deepen the technology use as well as possibly scaling it up for other hospitals. Business leadership, after reaching a level of acceptance of transparency/accountability culture through the rtDashboard, has started to promote the regionalization of this alignment process.

Such an inter-weaving of hospital and IT leadership, referred to here as DL practice, is essential if hospitals and organizations, in general, are to be digitally prepared to address the rapid market transformations occurring today.

In summary, IT leadership used flexibility in rtDashboard implementation during the early stages to reduce uncertainty among user groups, ${ }^{[22]}$ and looked for standardization later for broadening the technology use and scaling it for wider regional use. Business leadership proactively used rich media for communication to reduce equivocality contributed by departmental differentiation and task complexity in the early stages, and used flexibility in the later stages by allowing unit leaders with varying degrees of diverse knowledge to interact with each other and engage in interactive discourse for conflict resolution.

Figure 4 shows where SJMO is as of March 2016 in their assimilation of the three innovations: rtDashboard, change in culture, and DL practice. The rtDashboard is widely used by all stakeholders involved in management and is being expanded for other hospitals. The cultural change of accountability/transparency is continually practiced at the senior and unit level management, and this is an on-going journey. Process innovations such as cultural change need constant nurturing as the hospital engages in newer innovations and brings in new leadership. The DL, as it was practiced here, is one operationalization of the building blocks of digital readiness, ${ }^{[22,23]}$ where innovative digital services, derived from competitive needs, are supported by effective interaction between business and IT leaders.

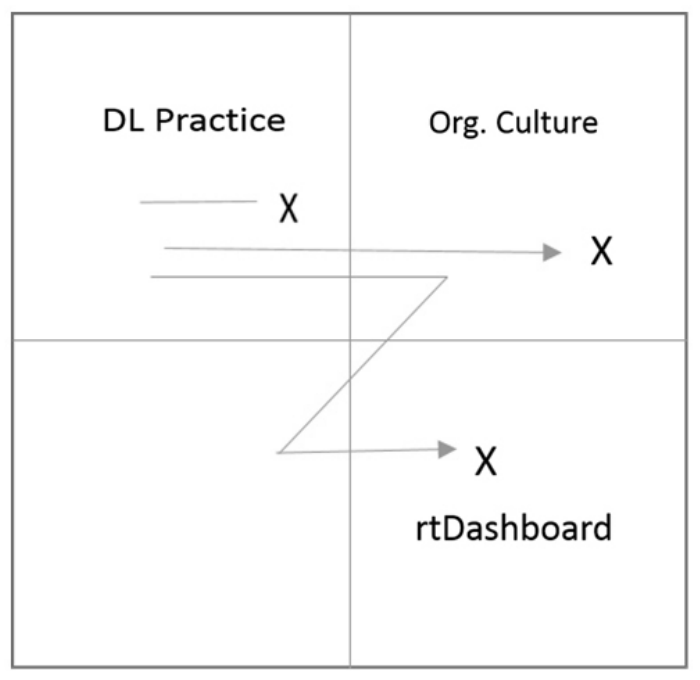

Figure 4. SJMO's assimilation strategies

\section{Conclusions}

In conclusion, with this case study, our contribution is to show how a hospital has become digitally ready by using one particular innovation to create a culture of transparency/accountability, and how it tested its DL capability to take advantage of future digitization opportunities. The combined effort of hospital and IT leaders in fact led to not only gaining external recognition for the effort (Wired Magazine Innovation Award Finalist, 2015; www . hhnmag . com), but also led to its adoption of several other innovations. This is often referred to as improving an organization's digital quotient. ${ }^{[25]}$

\section{REFERENCES}

[1] Lusch RF, Vargo SL, Tanniru M. Service, value networks and learning. Journal of the Academy of Marketing Science. 2009; 38(1): 19-31. http://dx.doi.org/10.1007/s11747-008-0131-z

[2] Vargo SL, Lusch RF. Service-dominant logic: continuing the evo- lution. Journal of the Academy of Marketing Science. 2008; 36(1): 1-10. http://dx.doi.org/10.1007/s11747-007-0069-6

[3] Nanry J, Narayanan S, Rassey L. Digitizing the value chain. McKinsey Quarterly. 2015; 3(1).

[4] Grant RM. The resource-based theory of competitive advantage: im- 
plications for strategy formulation. California Management Review. 1991; 33(3): 114-135. http://dx.doi .org/10.2307/41166664

[5] Lavie D. Capability reconfiguration: An analysis of incumbent responses to technological change. Academy of Management Review. 2006; 31(1): 153-174. http://dx.doi.org/10.5465/AMR.200 6.19379629

[6] Ives B, Vitale MR. After the sale: Leveraging maintenance with information technology. MIS Quarterly. 1988; 12(1): 7-21. http: //dx.doi.org/10.2307/248797

[7] Mithas S, Krishnan MS, Fornell C. Why do customer relationship management applications affect customer satisfaction? Journal of Marketing. 2005; 69(4): 201-209. http://dx.doi.org/10.1509 /jmkg. 2005.69.4.201

[8] Bossert O, Laartz J, Ramsøy TJ. Running your company at two speeds. McKinsey \& Company. 2014.

[9] Rai A, Ramaprasad A, Bajwa DS. The structural context of executive information systems adoption. Information Resources Management Journal. 1998; 11(3): 28-38. http://dx.doi.org/10.4018/irm j. 1998070103

[10] Pierce JL, Delbecq AL. Organization structure, individual attitudes and innovation. Academy of Management Review. 2016; 10(1): 341344.

[11] Thompson VA. Bureaucracy and innovation. Admin Sci Quart. 1965; 10: 1-20. http://dx.doi.org/10.2307/2391646

[12] Zaltman G, Duncan R, Holbek J. Innovations and Organizations. New York: Wiley; 1973. PMid: 4266790.

[13] Rogers EM. Diffusion of Innovations, $3^{r d}$ ed. New York: Free Press; 1983.

[14] Mergel I, Bretschneider SI. A three stage adoption process for social media use in government. Public Administration Review. 2013; 73(3): 390-400. http://dx.doi.org/10.1111/puar.12021

[15] Agarwal R, Tanniru M, Wilemon D. Assimilating information technology innovations: strategies and moderating influences. Engi- neering Management, IEEE Transactions. 1997; 44(4): 347-358. http://dx.doi.org/10.1109/17.649864

[16] Fichman R. Alternative measures of organizational innovativeness: a conceptual and empirical analysis. Annual Diffusion Interest Group in Information Technology Workshop, Vancouver, BC. 1994.

[17] Ash JS. Factors for information technology innovation diffusion and infusion in health sciences organizations: A systems approach Portland State University. 1997.

[18] Legris P, Ingham J, Collerette P. Why do people use information technology - a critical review of the technology acceptance model. Information \& Management. 2003; 40(3): 191-204. http: //dx.doi.org/10.1016/S0378-7206(01) 00143-4

[19] Venkatesh V, Davis FD. A theoretical extension of the technology acceptance model: four longitudinal field studies. Management Science. 2000; 46(2): 186-204. http://dx.doi.org/10.1287/mns c. 46.2 .186 .11926

[20] Sharif MHM, Troshani I, Davidson R. Public Sector Adoption of Social Media. Journal of Computer Information Systems. 2015; 55(4): 53-61. http://dx.doi.org/10.1080/08874417.2015 .11645787

[21] Rogers EM, Shoemaker FF. Communication of Innovations: A CrossCultural Approach. N.Y.: The Free Press; 1971.

[22] Cooper RB, Wolfe RA. Information processing model of information technology adaptation: an intra-organizational diffusion perspective. Data Base for Advances in Information Systems. 2005; 36(1): 30-48. http://dx.doi.org/10.1145/1047070.1047074

[23] Catlin T, Scanlan J, Willmott P. Raising your digital quotient. McKinsey Quarterly. 2014.

[24] Desmet D, Duncan E, Scanlan J, et al. Six building blocks for creating high-performing digital enterprises. McKinsey \& Company. 2015.

[25] Global Digital IQ Survey. lessons from digital leaders: 10 attributes driving organizational performance. Price Waterhouse Coopers. 2015. 